\title{
Acute toxicity of second generation HIV protease-inhibitors in combination with radiotherapy: a retrospective case series
}

\author{
Alfred P See ${ }^{1 \dagger}$, Jing Zeng ${ }^{2 \dagger}$, Phuoc T Tran ${ }^{2,3^{*}}$, Michael Lim ${ }^{1,3}$
}

\begin{abstract}
Background: There is little data on the safety of combining radiation therapy and human immunodeficiency virus (HIV) protease inhibitors to treat cancers in HIV-positive patients. We describe acute toxicities observed in a series of HIV-positive patients receiving modern radiation treatments, and compare patients receiving HIV protease inhibitors (PI) with patients not receiving HIV PIs.
\end{abstract}

Methods: By reviewing the clinical records beginning January 1, 2009 from the radiation oncology department, we identified 29 HIV-positive patients who received radiation therapy to 34 body sites. Baseline information, treatment regimen, and toxicities were documented by review of medical records: patient age, histology and source of the primary tumor, HIV medication regimen, pre-radiation CD4 count, systemic chemotherapy, radiation therapy dose and fractionation, irradiated body region, toxicities, and duration of follow-up. Patients were grouped according to whether they received concurrent HIV PIs and compared using Pearson's chi-square test.

Results: At baseline, the patients in the two groups were similar with the exception of HIV medication regimens, CD4 count and presence of AIDS-defining malignancy. Patients taking concurrent Pls were more likely to be taking other HIV medications ( $p=0.001)$ and have CD4 count $>500(p=0.006)$. Patients taking Pls were borderline less likely to have an AIDS-defining malignancy $(p=0.06)$. After radiation treatment, 100 acute toxicities were observed and were equally common in both groups (64 [median 3 per patient, IQR 1-7] with Pls; 36 [median 3 per patient, IQR 2-3] without PIs). The observed toxicities were also equally severe in the two groups (Grades I, II, III respectively: 30, 30, 4 with PIs; 23, 13, 0 without PIs: $p=0.38$ ). There were two cases that were stopped early, one in each group; these were not attributable to toxicity.

Conclusions: In this study of recent radiotherapy in HIV-positive patients taking second generation PIs, no difference in toxicities was observed in patients taking Pls compared to patients not taking Pls during radiation therapy. This suggests that it is safe to use unmodified doses of Pls and radiation therapy in HIV cancer patients, and that it is feasible to use Pls as a radiosensitizer in cancer therapy, as has been suggested by pre-clinical results.

\section{Background}

HIV and malignancies

Historically, HIV infection is associated with a much higher risk of specific cancers [1-4]. In particular, diagnosis of Kaposi sarcoma, non-Hodgkin lymphoma (NHL), or cervical cancer are considered acquired

\footnotetext{
* Correspondence: tranpt21@sbcglobal.net

+ Contributed equally

2Department of Radiation Oncology and Molecular Radiation Sciences, The Sidney Kimmel Comprehensive Cancer Center, The Johns Hopkins Hospital, 401 North Broadway, Baltimore, MD, 21231 USA

Full list of author information is available at the end of the article
}

immunodeficiency syndrome (AIDS)-defining malignancies [5]. However, increasing effectiveness of anti-retroviral therapy (ART) has led to decreased mortality in Europe and North America from opportunistic infections and AIDS-defining malignancies [5-8], while mortality from non-AIDS-defining and non-HIV-associated cancers has been increasing $[8,9]$.

Response to cancer therapy is also different in the HIV patient population. Initial reports found increased radiotoxicity in HIV patients receiving treatment for Kaposi sarcoma, cervical carcinoma, while there was no difference in adverse effects of radiation therapy for

\section{() Biomed Central}

(c) 2011 See et al; licensee BioMed Central Ltd. This is an Open Access article distributed under the terms of the Creative Commons Attribution License (http://creativecommons.org/licenses/by/2.0), which permits unrestricted use, distribution, and reproduction in any medium, provided the original work is properly cited. 
other malignancies $[10,11]$. Systemic glutathione deficiency [12], DNA repair deficiency, or cell cycle dysregulation may increase radiosensitivity [13-15]. However, radiation therapy remains a cornerstone of therapy in a number of cancers such as anal cancer [16], prostate [17], breast [18-20], and cervical cancer [16,21].

\section{Protease inhibitors in the treatment of HIV}

PIs are anti-viral drugs that inhibit proteases, viral enzymes which cleave polyprotein precursors into mature viral proteins [22]. PIs are one class of anti-virals that is used as the 'base' in combination with two 'backbone' drugs for treatment of HIV, antiretroviral therapy (ART). There are currently ten PIs available; in chronological order of FDA approval, saquinavir, ritonavir, indinavir, nelfinavir, lopinavir, atazanavir, fosamprenavir (pro-drug of amprenavir, which is no longer available), tipranavir, and darunavir.

Although PIs act by inhibiting HIV aspartyl protease, they also have off-target effects. The entire class is associated with dysregulation of glucose and lipid metabolism due to homology between HIV-1 protease and various human proteins [23-26]. In addition, some PIs inhibit the phosphatidyl-inositol 3-kinase (PI3K)-Akt pathway, which is shared by numerous cell homeostasis pathways $[27,28]$.

\section{Non-target effects of protease inhibitors}

A number of PIs have been associated with anti-cancer activity [29]. Through PI3K-Akt and closely related pathways, PIs induce apoptosis of tumor cells [30-36]. Although PIs have been shown to directly effect tumor cell death, use of PIs has not reduced cancer risk in HIV patients, suggesting that PIs would not be clinically effective anti-cancer monotherapies [37]. Although ineffective alone, PIs synergize with other cancer therapies such as radiotherapy [38].

Initial studies suggested that nelfinavir upregulates vascular endothelial growth factor (VEGF) and downregulates hypoxia-inducible factor 1 alpha (HIF-1 $\alpha$ ). Although VEGF can increase tumor oxygenation, the HIF1- $\alpha$ hypoxia factor can mediate radiation resistance $[39,40]$. However, HIF-1 $\alpha$ knockdown studies suggest that radiosensitivity induced by PIs is independent of HIF-1 $\alpha$ [28,40-42]. In a number of cancers, resistance to radiotherapy is mediated by the PI3K-Akt pathway, suggesting an alternative mechanism of PI-induced radiosensitization [43-45]. Preclinical studies with nelfinavir in head-and-neck cancer [46] and non-small cell lung cancer [28] cell lines found downregulation of Akt to be associated with increased sensitivity to radiation.

Although PI-induced radiosensitization of cancers was shown to be independent of HIF-1 $\alpha$, PIs have been shown to induce systemic vascular stress [47]. Preclinical in vivo studies suggest that in addition to direct effect on the tumor cells, PIs may inhibit PI3K-Akt activation in tumor vasculature, suppressing hypoxia pathways and leading to reduced radiation resistance $[48,49]$. Other clinical reports also suggest that PIs and radiotherapy interact on tumor vasculature similar to the effects of radiation and bevacizumab, an anti-angiogenic antibody [50].

\section{Protease inhibitors and radiotherapy}

A retrospective review (14 patients receiving PIs and 28 controls) did not find severe toxicities attributable to combination of PIs and radiotherapy for cancer in HIV+ patients [11,51-54]. There are ten prospective trials, nine of which are on-going (a phase II trial was terminated due to poor enrollment): five phase I studies, and four studies that have a phase II component. One published phase I trial in pancreatic cancer showed the following toxicites one of which was life-threatening: severe nausea and vomiting and increase in liver enzymes and bilirubin due to stent occlusion [55]. Given the inconclusive safety data on combining PIs and radiation therapy to treat cancer in HIV patients, we reviewed a series of HIV patients receiving radiation therapy for malignancies.

\section{Methods}

\section{Patient identification}

In accordance with a research protocol approved by the Institutional Review Board, patients were identified by review of clinical records from January 1, 2009-October 31, 2010 in the Department of Radiation Oncology at The Johns Hopkins Hospital. Patients were included if they had documented HIV infection and received radiation therapy at Johns Hopkins.

\section{Retrospective review}

Medical records for included patients were reviewed for HIV medications, cancer diagnosis and stage, radiation therapy (site, dose, fractionation, completion or early stopping), age at time of radiation therapy, cancer chemotherapy, acute $(<6$ weeks after end of radiation therapy) toxicities categorized by Common Toxicity Criteria for Adverse Events version 3.0 (CTCAE) grade. All patients receiving radiation therapy were evaluated at least once per week for treatment toxicity, and side effects were recorded prospectively in an electronic record system.

\section{Statistical analysis}

Patients were categorized by type of malignancy (AIDSdefining, HIV-associated, non-HIV associated), taking non-PI HIV medications (yes/no), and by baseline CD4 count $(<50,<200,<500,500)$. Toxicities were categorized 
by CTCAE grade. Differences between the groups were analyzed using Pearson's chi-square test with JMP 8.0 (SAS Institute Inc.). Statistical significance was defined as a Pearson's chi-square p-value $<0.05$.

\section{Results}

We retrospectively reviewed acute toxicities in a series of patients with a history of HIV infection and receiving radiation therapy; in this series, we compared patients who received concurrent PIs with patients who did not receive concurrent PIs. Eighteen patients received concurrent PIs and radiation therapy; one patient received radiation therapy for two different malignancies, and one patient received radiation for three recurrences of NHL. There were eleven patients with a history of HIV infection but not treated with PIs who received radiation therapy; one patient received three regimens of radiation therapy, twice for brain metastasis and once for testicular metastasis.

\section{Patient characteristics}

Characteristics of patients receiving concurrent protease inhibitor are presented in Table 1 while characteristics of patients not receiving concurrent protease inhibitor are presented in Table 2. There were 34 total courses of radiation treatment delivered (21 with PIs, 13 without PIs) for a variety of histologies, including HIV-defining (0 with PIs; 3 [23\%] without PIs), HIV-associated (11 [58\%] with PIs; 5 [38\%] without PIs), non-HIV-associated malignancies (8 [42\%] with PIs, 5 [38\%] without PIs), and non-malignancies (keloid scar and dural arteriovenous fistula with PIs, none without PIs). The median age was 50 (interquartile range [IQR] 47-56). The difference between the two groups in number of AIDS-

Table 1 Baseline data: patients receiving concurrent protease inhibitor

\begin{tabular}{|c|c|c|c|c|c|c|}
\hline$\#$ & Cancer diagnosis & Age & $\begin{array}{l}\text { Concurrent systemic } \\
\text { therapy }\end{array}$ & $\begin{array}{l}\text { Baseline } \\
\text { CD4 }\end{array}$ & Non-PI HIV regimen & PI \\
\hline $1 \mathrm{a}$ & Ductal carcinoma, breast T2N1M0 & 47 & None & 104 & lamivudine, raltegravir & RTV, DRV \\
\hline $1 b$ & SCC, anus T3NOMO & 49 & 5-FU, mitomycin C & 68 & lamivudine, raltegravir & RTV, DRV \\
\hline 2 & SCC, vulva T1bN1b, stage IIla & 26 & cisplatin & 1647 & emtricitabine, tenofovir & RTV, ATZ \\
\hline 3 & Ductal carcinoma, breast T1cNOMO, stage I & 47 & None & 474 & $\begin{array}{l}\text { emtricitabine, tenofovir, } \\
\text { raltegravir }\end{array}$ & RTV, ATZ \\
\hline 4 & SCC, anus T2NOMO, stage $\|$ & 47 & None & NR & $\begin{array}{l}\text { emtricitabine, tenofovir, } \\
\text { raltegravir }\end{array}$ & RTV, DRV \\
\hline 5 & $\begin{array}{c}\text { Adenocarcinoma, prostate cT2bNXM0, GS 3+3, PSA } \\
8.7 \text {, stage } \|\end{array}$ & 58 & None & WNL & $\begin{array}{l}\text { efavirenz, emtricitabine, } \\
\text { tenofovir }\end{array}$ & RTV, LPV \\
\hline 6 & $\begin{array}{c}\text { Adenocarcinoma, prostate cT1 cNXMO, GS 3+4, PSA } \\
4.9 \text {, stage } \|\end{array}$ & 73 & androgen deprivation & 1105 & raltegravir & RTV, DRV \\
\hline 7 & $\begin{array}{c}\text { Adenocarcinoma, prostate cT1cNXM0, GS 4+3, PSA } \\
5.1 \text { stage } \|\end{array}$ & 69 & androgen deprivation & 536 & abacavir, lamivudine & RTV, ATZ \\
\hline 8 & $\begin{array}{c}\text { Renal cell carcinoma, lateral chest wall, metastatic, } \\
\text { stage IV }\end{array}$ & 50 & sutent & 766 & $\begin{array}{l}\text { emtricitabine, tenofovir, } \\
\text { efavirenz }\end{array}$ & RTV, ATZ \\
\hline 9 & Arteriovenous fistula, dura mater & 57 & None & 944 & abacavir, lamivudine, raltegravir & RTV, LPV \\
\hline 10 & SCC, tonsil T2N2bM0 & 53 & cisplatin & 956 & emtricitabine, tenofovir & RTV, LPV \\
\hline \multirow[t]{2}{*}{11} & Primary CNS Iymphoma, CNS & 44 & None & 4 & None & RTV, DRV \\
\hline & & & doxil, cytoxan, & & & \\
\hline 12 & NHL, neck and axilla, stage IV & 53 & vincristine, prednisone & 57 & abacavir, lamivudine & RTV \\
\hline $13 a$ & NHL, pelvis, stage IV & 53 & None & 120 & abacavir, lamivudine & RTV, ATZ \\
\hline $13 b$ & $\mathrm{NHL}$, axilla, stage IV & 55 & None & 39 & abacavir, lamivudine & RTV, LPV \\
\hline $13 c$ & NHL, temple, stage IV & 56 & None & 87 & abacavir, lamivudine & RTV, LPV \\
\hline 14 & Primary CNS lymphoma, CNS & 21 & None & 0 & emtricitabine, tenofovir & RTV, DRV \\
\hline 15 & Ductal carcinoma, breast T2NOMO, stage lla & 58 & None & NR & emtricitabine, tenofovir & RTV, LPV \\
\hline 16 & SCC, anus T1N0M0, stage I & 43 & 5-FU, mitomycin C & 547 & abacavir, lamivudine & RTV, LPV \\
\hline 17 & Primary CNS Iymphoma, CNS & 23 & None & 10 & emtricitabine, tenofovir & RTV, DRV \\
\hline 18 & Keloid scar, posterior scalp & 47 & None & WNL & $\begin{array}{l}\text { zidovudine } 300 \text { mg, } \\
\text { lamivudine } 150 \text { mg }\end{array}$ & NFV \\
\hline
\end{tabular}

Patients are uniquely identified by numbers, repeated treatments on a patient are distinguished by a letter after the number.

$\mathrm{NHL}=$ non-Hodgkin lymphoma.

$\mathrm{CT}=$ clinical tumor, $\mathrm{pT}=$ pathological tumor, $\mathrm{GS}=$ Gleason score, $\mathrm{PSA}=$ prostate specific antigen .

RTV = ritonavir, DRV = darunavir, ATZ = atazanavir, LPV = lopinavir, NFV = nelfinavir.

WNL $=$ Reported as within normal limits, NR $=$ not reported. 
Table 2 Baseline data: patients not receiving concurrent protease inhibitor

\begin{tabular}{|c|c|c|c|c|c|}
\hline$\#$ & Cancer diagnosis & Age & $\begin{array}{c}\text { Concurrent } \\
\text { systemic therapy }\end{array}$ & $\begin{array}{l}\text { Baseline } \\
\text { CD4 }\end{array}$ & Non-PI HIV regimen \\
\hline 1 & SCC, cervix T4N1M0, stage IVa & 29 & cisplatin & 189 & None \\
\hline 2 & SCC, cervix, stage IIb & 34 & cisplatin & 189 & None \\
\hline 3 & Cholangiocarcinoma, abdomen pT3N1M0 & 53 & xeloda & 300 & efavirenz, emtricitabine, tenofovir \\
\hline 4 & Adenocarcinoma, prostate TXNXM1, stage IV & 48 & None & 399 & None \\
\hline 5 & Meningioma, CNS & 46 & None & 408 & None \\
\hline 6 & $\begin{array}{c}\text { Adenocarcinoma, prostate cT1cNXMO, GS } \\
\qquad 3+4 \text {, PSA 20.6, stage } \|\end{array}$ & 62 & $\begin{array}{l}\text { androgen } \\
\text { deprivation }\end{array}$ & 1047 & None \\
\hline 7 & NSCLC, brain met, stage IV & 57 & None & NR & None \\
\hline $8 a$ & DLBCL, brain met, stage IV & 46 & None & 214 & efavirenz, emtricitabine, tenofovir \\
\hline $8 b$ & DLBCL, brain met recurrence, stage IV & 46 & None & 214 & efavirenz, emtricitabine, tenofovir \\
\hline $8 c$ & DLBCL, testicular met, stage IV & 46 & None & 214 & efavirenz, emtricitabine, tenofovir \\
\hline 9 & $\begin{array}{c}\text { Adenocarcinoma, prostate cT2aNXMO, GS } \\
\qquad 3+4, \text { PSA } 1.1 \text {, stage ॥ }\end{array}$ & 61 & None & 150 & efavirenz, emtricitabine, tenofovir \\
\hline 10 & SCC, cervix, stage IIIb & 57 & cisplatin & 116 & None \\
\hline 11 & SCC, anal & 49 & $\begin{array}{l}\text { mitomycin } C \text { and } \\
\text { xeloda }\end{array}$ & 450 & efavirenz, emtricitabine, tenofovir \\
\hline
\end{tabular}

Patients are uniquely identified by numbers, repeated treatments on a patient are distinguished by a letter after the number.

$\mathrm{NHL}=$ non-Hodgkin lymphoma, $\mathrm{DLBCL}=$ diffuse large B-cell lymphoma.

$\mathrm{cT}=$ clinical tumor, $\mathrm{pT}=$ pathological tumor, $\mathrm{GS}=$ Gleason score, $\mathrm{PSA}=$ prostate specific antigen .

$\mathrm{NR}=$ not reported.

defining malignancies almost reached statistical significance $(\mathrm{p}=0.06)$, but the remainder of the malignancies (HIV-associated and non-HIV-associated) are not differently distributed in the two groups $(\mathrm{p}=0.9) .29$ cases had documented pre-treatment CD4 counts; 4 were $<50$ (4 [24\%] with PIs), 13 were <200 (9 [53\%] with PIs, 4 [33\%] without PIs), and 21 were $<500$ (10 [59\%] with PIs; 11[92\%] without PIs). Patients taking PIs were more likely than patients not taking PIs to have a CD4 count $\geq 500$ (7 [41\%] with PIs; 1 [8\%] without PIs; p$0.006)$.

\section{Radiation treatment}

For the 29 patients receiving radiation therapy, 15 patients were treated with definitive or adjuvant dose regimens (9 receiving PIs, 6 without PIs), while 14 patients received palliative radiation doses ( 9 receiving PIs, 5 without PIs). The exact definition of definitive/ adjuvant versus palliative dose varied based on body site. Definitive/adjuvant dose was at least 5400 cGy for brain (conventional fractionation equivalent), 7000 cGy for head and neck, 5400 cGy for breast, 4500 cGy for pelvis, and 7800 cGy for prostate. Palliative doses also varied based on body site and disease histology, but were lower than definitive/adjuvant dose regimens.

\section{HIV medications and systemic chemotherapy}

Systemic chemotherapy regimens for these two groups of patients are presented (Table 1 and 2). Of the 32 treatments for cancer (19 with PIs, 13 without PIs), 13 included systemic chemotherapy regimens (7 [37\%] with PIs; 6 [46\%] without PIs). 21 of the 29 patients were receiving HIV medications (17 [94\%] with PIs; 4 [36\%] without PIs; $\mathrm{p}=0.001$ ).

In the group receiving PIs, the most common PI was ritonavir (20 [95\%]), followed by darunavir and lopinavir (7 [33\%] each), atazanavir (5 [24\%]), and only one [5\%] patient received nelfinavir (Table 1 and 2).

\section{Toxicities}

Follow-up and observed toxicities are presented in Table 3 and 4 . The median follow-up of all patients was 18 weeks [IQR 8-30], but the follow-up for patients not taking PIs (median 13 weeks [IQR 5-18]) was much shorter than the follow-up for patients taking PIs (median 21 weeks [IQR 10-38]). The limited follow-up in the group not taking PIs prevented comparison of longterm toxicities.

There were 64 acute toxicities in the group receiving PIs (30 grade 1, 30 grade 2, 4 grade 3 ). In the group not receiving PIs, there were 36 acute toxicities (23 grade 1 , 13 grade 2). The median number of toxicities experienced per patient was not different between the groups (3 [IQR 1-7] with PIs; 3 [IQR 2-3] without PIs). Chisquare analysis of the distribution of severity did not find statistically significant difference in the severity of toxicities between the two groups $(\mathrm{p}=0.38)$. One radiation treatment in each group was stopped early, but neither of these was secondary to toxicity (no grade 3 toxicities in either patient). 
Table 3 Radiation regimen, follow-up and toxicities in patients receiving concurrent protease inhibitor

\begin{tabular}{|c|c|c|c|c|c|}
\hline$\#$ & $\begin{array}{c}\text { F/U } \\
{[\text { weeks] }}\end{array}$ & Region treated & $\begin{array}{c}\text { Dose } \\
\text { (fractionation) } \\
\text { [cgy] }\end{array}$ & $\begin{array}{l}\text { Complete } \mathrm{RT} \\
\text { regimen }\end{array}$ & Acute toxicity and CTC grade \\
\hline $1 \mathrm{a}$ & 75 & right breast & $5800(200)$ & yes & dermatitis 2 , pruritis 1 , hyperpigmentation 2, fatigue 1 , pain 1 \\
\hline \multirow[t]{2}{*}{$1 b$} & 0 & pelvis & $3600(180)$ & $\begin{array}{l}\text { no, prescribed } \\
5400\end{array}$ & fatigue 2 , pain 2, nocturia 2, anorexia 1, proctitis 2 \\
\hline & & & & & fatigue 1 , pain 1 , nocturia and urinary \\
\hline \multirow[t]{2}{*}{2} & 9 & pelvis and left vulva & $4500(180)$ & yes & frequency 1 , dysuria 2 , proctitis 1 , diarrhea \\
\hline & & & & & 1 , mucosal drainage 1 \\
\hline 3 & 36 & right breast & $5130(270)$ & yes & fatigue 2 , pain 3 , dermatitis 1 , hyperpigmentation 2 \\
\hline 4 & 18 & pelvis and anus & $3000(200)$ & yes & dysuria 1 \\
\hline 5 & 82 & prostate and SV & $6720(320)$ & yes & $\begin{array}{c}\text { dysuria and nocturia and urinary frequency 2, anorexia 1, diarrhea 1, } \\
\text { hematochezia } 1\end{array}$ \\
\hline 6 & 18 & prostate and SV & $8000(200)$ & yes & nocturia and urinary frequency 2 \\
\hline 7 & 7 & prostate and SV & $7800(200)$ & yes & $\begin{array}{c}\text { pain 1, dysuria and urinary frequency and incontinence } 2, \\
\text { constipation 1, diarrhea } 1\end{array}$ \\
\hline 8 & 8 & left lateral chest wall & $3600(300)$ & yes & dermatitis 1 \\
\hline 9 & 38 & brain & $2000(2000)$ & yes & none \\
\hline 10 & 25 & head and neck & $7000(200)$ & yes & dermatitis 3, fatigue 3, dysphonia 1, xerostomia 2 \\
\hline 11 & 21 & brain & $3000(300)$ & yes & fatigue 2, pain 2, nausea 2, insomnia 2, anorexia 2, vomiting 2, ataxia 2 \\
\hline 12 & 23 & right neck and left axilla & $3000(200)$ & yes & fatigue 1 , pain 1 , dermatitis 1 , dysgeusia 1 , dysphonia 1 , xerostomia 1 \\
\hline $13 a$ & 147 & right pelvis & $3000(250)$ & yes & fatigue 1 \\
\hline $13 b$ & 13 & $\begin{array}{l}\text { right axilla and ulcerating } \\
\text { skin lesion }\end{array}$ & $3060(180)$ & yes & dermatitis 2 , drainage 3 , pruritus 1 \\
\hline $13 c$ & 7 & $\begin{array}{l}\text { right temple and } \\
\text { subcutaneous skin lesion }\end{array}$ & $3060(180)$ & yes & dermatitis 2 \\
\hline 14 & 19 & brain & $3000(300)$ & yes & fatigue 1 \\
\hline 15 & 86 & right breast & $6000(200)$ & yes & dermatitis 1 \\
\hline 16 & 85 & pelvis & $5040(180)$ & yes & $\begin{array}{c}\text { fatigue } 1 \text {, pain } 2 \text {, nausea } 1 \text {, nocturia and } \\
\text { urinary frequency } 1 \text {, anorexia } 2 \text {, proctitis } 1 \text {, } \\
\text { diarrhea } 2 \text {, dermatitis } 2\end{array}$ \\
\hline 17 & 10 & brain & $3000(300)$ & yes & altered mental status in intensive care throughout treatment \\
\hline 18 & 31 & posterior scalp & $1600(400)$ & yes & none \\
\hline
\end{tabular}

Patients are uniquely identified by numbers, repeated treatments on a patient are distinguished by a letter after the number.

$\mathrm{F} / \mathrm{U}=$ follow-up.

\section{Discussion}

Our retrospective review of HIV-positive patients receiving radiation therapy found no increased toxicity in patients receiving concurrent PIs. The number and severity of toxicities experienced per patient were not found to be different in patients who were concurrently taking PIs compared to those who were not. There were differences in the baseline characteristics and medication regimens of the two groups. First, there were no cases of AIDS-defining malignancies in the group treated with PIs. This difference coincided with a difference in all HIV treatment and CD4 count. Significantly more patients in the non-PI group did not receive any medication to manage HIV, and significantly more patients in the non-PI group had CD4 counts below 500. This difference may reflect the efficacy of PIs and ART in controlling HIV, and a resulting decrease in opportunistic malignancies that has been observed with progressive generations of ART[9]. Although ART is typically initiated if the CD4 count is below 500, there are a number of other factors that contribute to the decision to initiate therapy, such as patient preference, adherence to prescriptions, and HIV strain. There was no association between CD4 count and adverse events.

There have been a number of case reports and small case series documenting seve re toxicities in HIV patients receiving radiation therapy. A meta-analysis of case reports and case series found severe toxicities in HIV patients receiving radiation therapy for Kaposi sarcoma and cervical carcinoma, but not in other malignancies [10]. Our results are in accordance with the only published study evaluating toxicities from interaction between PIs and radiation therapy [11]. Plastaras et al. reviewed 14 patients with concurrent PIs and 28 patients in the absence of PI, and found no difference in toxicity from radiation therapy. Although this group 
Table 4 Radiation regimen, follow-up and toxicities in patients not receiving concurrent protease inhibitor

\begin{tabular}{cccccc}
\hline$\#$ & $\begin{array}{c}\text { F/U } \\
\text { [weeks] }\end{array}$ & Region treated & Dose (fractionation) [cgy] & $\begin{array}{c}\text { Complete RT } \\
\text { regimen }\end{array}$ & Acute toxicity and CTC grade \\
\hline 1 & 6 & Pelvis & $5400(180)$ & yes & fatigue 1, nocturia 1, proctitis 2, gastrointestinal bleed \\
, dermatitis 2
\end{tabular}

Patients are uniquely identified by numbers, repeated treatments on a patient are distinguished by a letter after the number.

$\mathrm{F} / \mathrm{U}=$ follow-up.

$\mathrm{HDR}=$ high dose radiation

found no increase in toxicity from radiation therapy, the patient series was treated between 1993-2007 for the control group and 1997-2006 for the PI group. Inclusion of patients from this time period may have been reflected in the distribution of PIs and the distribution of malignancies treated. Nearly all patients in the Plastaras et al. study were treated with nelfinavir, three were treated with saquinavir (the oldest available PI), and one was treated with amprenavir (no longer available). 29 (69\%) of 42 malignancies were AIDS-defining or strongly associated with HIV. These results may be limited by the baseline characteristics: AIDS-defining and HIV-associated malignancies are more heavily represented than in the current HIV+ population and PI regimens are evolving rapidly. Although not related to the years from which the patients were sampled, only 6 of the 14 patients from the PI group had documented CD4 count: one was $<50$, two were $<200$, and three $<500$. No association was observed between CD4 count and radiation toxicity, but the data is limited.

Our study characterizes the safety of radiation therapy combined with the newer generation of PIs in treatment of non-AIDS defining malignancies which are increasingly common in the era of improved ART. The series included only patients treated from January 1, 2009 onwards: of the 18 patients receiving PIs, 16 (89\%) were receiving a dual-PI regimen; only two were taking a mono-PI regimen (one ritonavir and one nelfinavir). The case series included more malignancies not associated with HIV or AIDS (ductal carcinoma of the breast, renal cell carcinoma, cholangiocarcinoma, and meningioma), and two non-malignancies (dural AVM, and keloid scar) that were treated with radiation. Half of the patients in this case series received definitive or adjuvant radiation dose regimens (45-78 Gy). These patients were distributed equally in the group with PIs and in the group without PIs, and combination of definitive/adjuvant doses of radiation with PIs did not increase toxicities over definitive/adjuvant radiation doses alone. The present study more than doubles the reported number of patients treated with HIV PIs and radiation from 14 to 32.

The limitations of this study include the small size, short follow-up, heterogeneous nature of our cohort, and the differences between the control group and the PI treatment group. As discussed before, in addition to not taking PI, the control group also received less nonPI HIV medications and had a lower median CD4 count. The factors that underlie these two differences may confound the results. In addition, although we collected data on late toxicities, there was insufficient follow-up (21 weeks [IQR 10-38] with PIs, 13 [IQR 5-18] without PIs) to assess differences in late toxicities. Extended follow-up is necessary to determine the impact on long term toxicities. In addition, the majority of the cases received ritonavir combined with a second PI. Ritonavir does not inhibit Akt, which is a proposed 
mechanism of radiosensitization by PIs [27]. However, there are no published studies evaluating the radiosensitizing effect of darunavir, atazanavir, or lopinavir, which were used in combination with ritonavir by the majority of the patients. Prior studies on radiosensitization by PIs have not found a defining structural characteristic which would predict whether a PI will increase radiosensitivity. In spite of these limitations, this retrospective review provides valuable information about the acute toxicity of combining radiation with current PI therapies. Review of this contemporary series of patients did not find an increase in acute toxicity from the combination of the newest generation of HIV PIs and radiation therapy to treat diverse pathologies.

\section{Conclusions}

Preclinical data has suggested that PIs used in the treatment of HIV may radiosensitize cancer cells, but case reports have suggested that PIs may exacerbate radiotoxicity in normal tissue. Review of a set of HIV-positive radiation therapy patients did not reveal increased toxicity in patients taking PIs during radiation therapy. Our cohort doubles the number of patients in the current literature on the acute safety profile of combining PIs and radiation therapy. These data suggest that clinical trials of PIs as radiosensitizers will not encounter increased acute toxicity.

\section{Author details \\ 'Department of Neurosurgery, The Johns Hopkins Hospital, 600 N. Wolfe Street, Baltimore, MD 21287 USA. ²Department of Radiation Oncology and Molecular Radiation Sciences, The Sidney Kimmel Comprehensive Cancer Center, The Johns Hopkins Hospital, 401 North Broadway, Baltimore, MD, 21231 USA. ${ }^{3}$ Department of Oncology, The Sidney Kimmel Comprehensive Cancer Center, The Johns Hopkins Hospital, 401 North Broadway, Baltimore, MD, 21231 USA.}

\section{Authors' contributions}

APS identified the HIV-positive patients receiving radiation treatment, performed the statistical analysis and helped draft the manuscript. JZ designed the protocol, collected clinical variables in review of the patient records and helped draft the manuscript. PTT and ML conceived of the study, designed the study and edited the manuscript. All authors read and approved the final manuscript.

\section{Competing interests}

The authors declare that they have no competing interests.

Received: 16 December 2010 Accepted: 17 March 2011

Published: 17 March 2011

\section{References}

1. Guiguet M, Boue F, Cadranel J, Lang JM, Rosenthal E, Costagliola D, Clin Epidemiology Grp F-AC: Effect of immunodeficiency, HIV viral load, and antiretroviral therapy on the risk of individual malignancies (FHDH-ANRS CO4): a prospective cohort study. Lancet Oncology 2009, 10(12):1152-1159.

2. Shiels MS, Pfeiffer RM, Engels EA: Age at Cancer Diagnosis Among Persons With AIDS in the United States. Annals of Internal Medicine 2010 153(7):452-+.

3. Simard EP, Engels EA: Cancer as a Cause of Death among People with AIDS in the United States. Clinical Infectious Diseases 2010, 51(8):957-962.
4. Grogg KL, Miller RF, Dogan A: HIV infection and lymphoma. Journal of Clinical Pathology 2007, 60(12):1365-1372.

5. Silverberg MJ, Abrams DI: AIDS-defining and non-AIDS-defining malignancies: cancer occurrence in the antiretroviral therapy era. Current Opinion in Oncology 2007, 19(5):446-451.

6. Lima VD, Hogg RS, Harrigan PR, Moore D, Yip B, Wood E, Montaner JSG Continued improvement in survival among HIV-infected individuals with newer forms of highly active antiretroviral therapy. Aids 2007, 21:685-692.

7. Crum NF, Riffenburgh RH, Wegner S, Agan BK, Tasker SA, Spooner KM, Armstrong AW, Fraser S, Wallace MR, Triservice ACC: Comparisons of causes of death and mortality rates among HIV-infected persons Analysis of the pre-, early, and late HAART (highly active antiretroviral therapy) eras. Jaids-Journal of Acquired Immune Deficiency Syndromes 2006, 41(2):194-200

8. Lewden C, Salmon D, Morlat P, Bevilacqua S, Jougla E, Bonnet F, Heripret $L$, Costagliola D, May T, Chene G: Causes of death among human immunodeficiency virus (HIV)-infected adults in the era of potent antiretroviral therapy: emerging role of hepatitis and cancers, persistent role of AIDS. International Journal of Epidemiology 2005, 34(1):121-130.

9. Burgi A, Brodine S, Wegner S, Milazzo M, Wallace MR, Spooner K, Blazes DL, Agan BK, Armstrong A, Fraser $S$, et al: Incidence and risk factors for the occurrence of non-AIDS-defining cancers among human immunodeficiency virus-infected individuals. Cancer 2005, 104(7):1505-1511.

10. Housri N, Yarchoan R, Kaushal A: Radiotherapy for Patients With the Human Immunodeficiency Virus: Are Special Precautions Necessary? Cancer 2010, 116(2):273-283.

11. Plastaras JP, Vapiwala N, Ahmed MS, Gudonis D, Cerniglia GJ, Feldman MD, Frank I, Gupta AK: Validation and toxicity of PI3K/Akt pathway inhibition by HIV protease inhibitors in humans. Cancer Biology \& Therapy 2008, 7(5):628-635

12. Vallis KA: Glutathione deficiency and radiosensitivity in AIDS patients. Lancet 1991, 337(8746):918-919.

13. Baeyens A, Slabbert JP, Willem P, Jozela S, Van Der Merwe D, Vral A Chromosomal radiosensitivity of HIV positive individuals. International Journal of Radiation Biology 2010, 86(7):584-592.

14. Sun Y, Huang YC, Xu QZ, Wang HP, Bai B, Sul JL, Zhou PK: HIV-1 Tat depresses DNA-PKCS expression and DNA repair, and sensitizes cells to ionizing radiation. International Journal of Radiation Oncology Biology Physics 2006, 65(3):842-850

15. Chaurushiya MS, Weitzman MD: Viral manipulation of DNA repair and cell cycle checkpoints. DNA Repair 2009, 8(9):1166-1176.

16. Klas JV, Rothenberger DA, Wong WD, Madoff RD: Malignant tumors of the anal canal - The spectrum of disease, treatment, and outcomes. Cancer 1999, 85(8):1686-1693.

17. Eastham JA, Evans CP, Zietman A: What is the optimal management of high risk, clinically localized prostate cancer? Urologic Oncology-Seminars and Original Investigations 2010, 28(5):557-567.

18. Du XL, Freeman JL, Nattinger $A B$, Goodwin JS: Survival of women after breast conserving surgery for early stage breast cancer. Breast Cancer Research and Treatment 2002, 72(1):23-31.

19. Abe $O$, Abe $R$, Enomoto $K$, Kikuchi $K$, Koyama $H$, Masuda $H$, Nomura $Y$, Sakai K, Sugimachi K, Tominaga T, et al: Effects of radiotherapy and of differences in the extent of surgery for early breast cancer on local recurrence and 15-year survival: an overview of the randomised trials. Lancet 2005, 366(9503):2087-2106.

20. Srokowski TR, Fang SY, Duan ZG, Buchholz TA, Hortobagyi GN, Goodwin JS, Giordano SH: Completion of adjuvant radiation therapy among women with breast cancer. Cancer 2008, 113(1):22-29.

21. Stier E: Cervical neoplasia and the HIV-infected patient. HematologyOncology Clinics of North America 2003, 17(3):873-+.

22. Deeks SG, Smith M, Holodniy M, Kahn JO: HIV-1 protease inhibitors - A review for clinicians. Jama-Journal of the American Medical Association 1997, 277(2):145-153.

23. Behrens GMN, Boerner AR, Weber K, van den Hoff J, Ockenga J, Brabant G, Schmidt RE: Impaired glucose phosphorylation and transport in skeletal muscle cause insulin resistance in HIV-1-infected patients with lipodystrophy. Journal of Clinical Investigation 2002, 110(9):1319-1327.

24. Aboud M, Elgalib A, Kulasegaram R, Peters B: Insulin resistance and HIV infection: a review. International Journal of Clinical Practice 2007. 61(3):463-472. 
25. Carr A, Samaras K, Chisholm DJ, Cooper DA: Pathogenesis of HIV-1protease inhibitor-associated peripheral lipodystrophy, hyperlipidaemia, and insulin resistance. Lancet 1998, 351(9119):1881-1883.

26. Murata $H$, Hruz PW, Mueckler M: The mechanism of insulin resistance caused by HIV protease inhibitor therapy. Journal of Biological Chemistry 2000, 275(27):20251-20254

27. Gupta AK, Cerniglia GJ, Mick R, McKenna WG, Muschel RJ: HIV protease inhibitors block Akt signaling and radiosensitize tumor cells both in vitro and in vivo. Cancer Research 2005, 65(18):8256-8265.

28. Yang Y, Ikezoe T, Nishioka C, Bandobashi K, Takeuchi T, Adachi Y, Kobayashi M, Takeuchi S, Koeffler HP, Taguchi H: NFV, an HIV-1 protease inhibitor, induces growth arrest, reduced Akt signalling, apoptosis and docetaxel sensitisation in NSCLC cell lines. British Journal of Cancer 2006 95(12):1653-1662.

29. Bernstein WB, Dennis PA: Repositioning HIV protease inhibitors as cancer therapeutics. Curr Opin HIV AIDS 2008, 3(6):666-675.

30. Ikezoe T, Saito T, Bandobashi K, Yang Y, Koeffler HP, Taguchi H: HIV-1 protease inhibitor induces growth arrest and apoptosis of human multiple myeloma cells via inactivation of signal transducer and activator of transcription 3 and extracellular signal-regulated kinase 1/2. Molecular Cancer Therapeutics 2004, 3(4):473-479.

31. Jiang W, Mikochik PJ, Ra JH, Lei HQ, Flaherty KT, Winkler JD, Spitz FR: HIV protease inhibitor nelfinavir inhibits growth of human melanoma cells by induction of cell cycle arrest. Cancer Research 2007, 67(3):1221-1227.

32. Srirangam A, Mitra R, Wang M, Gorski JC, Badve S, Baldridge L, Hamilton J, Kishimoto H, Hawes J, Li L, et al: Effects of HIV protease inhibitor ritonavir on Akt-regulated cell proliferation in breast cancer. Clinical Cancer Research 2006, 12(6):1883-1896.

33. Yang Y, Ikezoe T, Takeuchi T, Adachi Y, Ohtsuki Y, Takeuchi S, Koeffler HP, Taguchi H: HIV-1 protease inhibitor induces growth arrest and apoptosis of human prostate cancer LNCaP cells in vitro and in vivo in conjunction with blockade of androgen receptor STAT3 and AKT signaling. Cancer Science 2005, 96(7):425-433.

34. Pyrko P, Kardosh A, Wang W, Xiong W, Schonthal AH, Chen TC: HIV-1 protease inhibitors nelfinavir and atazanavir induce malignant glioma death by triggering endoplasmic reticulum stress. Cancer Research 2007 67(22):10920-10928.

35. Gills J, Lo Piccolo J, Tsurutani J, Shoemaker RH, Best CJM, Abu-Asab MS, Borojerdi J, Warfel NA, Gardner ER, Danish M, et al: Nelfinavir, a lead HIV protease inhibitor, is a broad-spectrum, anticancer agent that induces endoplasmic reticulum stress, autophagy, and apoptosis in vitro and in vivo. Clinical Cancer Research 2007, 13(17):5183-5194

36. Pajonk F, Himmelsbach J, Riess K, Sommer A, McBride WH: The human immunodeficiency virus (HIV)-1 protease inhibitor saquinavir inhibits proteasome function and causes apoptosis and radiosensitization in non-HIV-associated human cancer cells. Cancer Research 2002, 62(18):5230-5235.

37. Crum-Cianflone NE, Hullsiek KH, Marconi V, Weintrob A, Ganesan A, Barthel RV, Fraser S, Roediger MP, Agan B, Regner S: The Impact of Nelfinavir Exposure on Cancer Development Among a Large Cohort of HIV-Infected Patients. Jaids-Journal of Acquired Immune Deficiency Syndromes 2009, 51(3):305-309.

38. Maggiorella L, Wen BX, Frascogna V, Opolon P, Bourhis J, Deutsch E: Combined radiation sensitizing and anti-angiogenic effects of ionizing radiation and the protease inhibitor Ritonavir in a head and neck carcinoma model. Anticancer Research 2005, 25(6B):4357-4362.

39. Pore N, Gupta AK, Cerniglia GJ, Jiang ZB, Bernhard EJ, Evans SM, Koch CJ, Hahn SM, Maity A: Nelfinavir down-regulates hypoxia-inducible factor 1 alpha and VEGF expression and increases tumor oxygenation: Implications for radiotherapy. Cancer Research 2006, 66(18):9252-9259.

40. Bachtiary B, Schindl M, Potter R, Dreier B, Knocke TH, Hainfellner JA, Horvat R, Birner P: Overexpression of hypoxia-inducible factor 1 alpha indicates diminished response to radiotherapy and unfavorable prognosis in patients receiving radical radiotherapy for cervical cancer. Clinical Cancer Research 2003, 9(6):2234-2240.

41. Arvold ND, Guha N, Wang DF, Matli M, Deen DF, Warren RS, HaasKogan DA: Hypoxia-induced radioresistance is independent of hypoxiainducible factor-1A in vitro. International Journal of Radiation Oncology Biology Physics 2005, 62(1):207-212.

42. Zou YF, Cheng C, Omura-Minamisawa M, Kang Y, Hara T, Guan XH, Inoue T: The Suppression of Hypoxia-inducible Factor and Vascular Endothelial
Growth Factor by siRNA Does not Affect the Radiation Sensitivity of Multicellular Tumor Spheroids. Journal of Radiation Research 2010, 51(1):47-55

43. Kim IA, Fernandes AT, Gupta AK, McKenna WG, Bernhard EJ: The influence of Ras pathway signaling on tumor radiosensitivity. Cancer and Metastasis Reviews 2004, 23(3-4):227-236.

44. Kim IA, Bae SS, Fernandes A, Wu JM, Muschel RJ, McKenna WG Birnbaum MJ, Bernhard EJ: Selective inhibition of Ras, phosphoinositide 3 kinase, and Akt isoforms increases the radiosensitivity of human carcinoma cell lines. Cancer Research 2005, 65(17):7902-7910.

45. Kimple RJ, Vaseva AV, Cox AD, Baerman KM, Calvo BF, Tepper JE, Shields JM, Sartor Cl: Radiosensitization of Epidermal Growth Factor Receptor/HER2-Positive Pancreatic Cancer Is Mediated by Inhibition of Akt Independent of Ras Mutational Status. Clinical Cancer Research 2010, 16(3):912-923.

46. Gupta AK, Lee JH, Wilke WW, Quon H, Smith G, Maity A, Buatti JM, Spitz DR Radiation response in two HPV-infected head-and-neck cancer cell lines in comparison to a non-hpv-infected cell line and relationship to signaling through AKT. International Journal of Radiation Oncology Biology Physics 2009, 74(3):928-933.

47. Chai H, Yang H, Yan SY, Li M, Lin PH, Lumsden AB, Yao Q, Chen CY: Effects of 5 HIV protease inhibitors on vasomotor function and superoxide anion production in porcine coronary arteries. Jaids-Journal of Acquired Immune Deficiency Syndromes 2005, 40(1):12-19.

48. Cuneo KC, Tu TX, Geng L, Fu AL, Hallahan DE, Willey CD: HIV protease inhibitors enhance the efficacy of irradiation. Cancer Research 2007, 67(10):4886-4893.

49. Edwards E, Geng L, Tan J, Onishko H, Donnelly E, Hallahan DE: Phosphatidylinositol 3-kinase/Akt signaling in the response of vascular endothelium to ionizing radiation. Cancer Research 2002, 62(16):4671-4677.

50. Chapman CH, Shen J, Filion EJ, Tran PT, Hara W, Asuncion A, Marko D, Wakelee H, Berry GJ, Dimmick KW, et al: Marked Tumor Response and Fatal Hemoptysis During Radiation for Lung Cancer in a Human Immunodeficiency Virus-Positive Patient Taking Nelfinavir. Journal of Thoracic Oncology 2009, 4(12):1587-1589.

51. Hocht S, Wiegel T, Kroesen AJ, Berdel WE, Runkel N, Hinkelbein W: Low acute toxicity of radiotherapy and radiochemotherapy in patients with cancer of the anal canal and HIV-infection. Acta Oncologica 1997, 36(8):799-802.

52. Edelman S, Johnstone PAS: Combined modality therapy for HIV-infected patients with squamous cell carcinoma of the anus: Outcomes and toxicities. International Journal of Radiation Oncology Biology Physics 2006, 66(1):206-211.

53. Place RJ, Gregorcyk SG, Huber PJ, Simmang CL: Outcome analysis of HIVpositive patients with anal squamous cell carcinoma. Diseases of the Colon \& Rectum 2001, 44(4):506-512.

54. Stadler RF, Gregorcyk SG, Euhus DA, Place RJ, Huber PJ, Simmang CL: Outcome of HIV-infected patients with invasive squamous-cell carcinoma of the anal canal in the era of highly active antiretroviral therapy. Diseases of the Colon \& Rectum 2004, 47(8):1305-1309.

55. Brunner TB, Geiger M, Grabenbauer GG, Lang-Welzenbach M, Mantoni TS, Cavallaro A, Sauer R, Hohenberger W, McKenna WG: Phase I trial of the human immunodeficiency virus protease inhibitor Nelfinavir and chemoradiation for locally advanced pancreatic cancer. Journal of Clinical Oncology 2008, 26(16):2699-2706.

doi:10.1186/1748-717X-6-25

Cite this article as: See et al:: Acute toxicity of second generation HIV protease-inhibitors in combination with radiotherapy: a retrospective case series. Radiation Oncology 2011 6:25. 